\title{
Axial Rotation in Rat Embryos: Involvement of Changes in the Shapes and Arrangement of Cells
}

\author{
Motoko Matsuda ${ }^{\dagger}$ and Masumi Yasutomi ${ }^{1}$ \\ Department of Embryology, Institute for Developmental Research, Kasugai, Aichi 480-03; and ${ }^{1}$ Laboratory of \\ Biology, Aichi Medical University, Nagakute, Aichi 480-11, Japan
}

Key words: Rat embryo/Axial rotation/Cytochalasin D/Phalloidin/Microfilament/Cell arrangement

\begin{abstract}
$A B S T R A C T$. Rat embryos at the head-fold stage (9.5 days of gestation) were cultured for 32 hours in rat serum. Embryos rotated their axes (changing from the shape of a concave mid-region to that of a convex mid-region) during the last 5 hours of culture (from $27 \mathrm{~h}$ to $32 \mathrm{~h}$ in culture). Addition of $0.1 \mu \mathrm{g} / \mathrm{ml}$ cytochalasin $\mathrm{D}$ to the culture medium for this 5 -hour period prevented axial rotation in the embryos and disturbed the appearance of microfilaments in the dermatome, the dorsal region of the trunk neural tube, and the dorsal epidermis. During the period of axial rotation, the dermatome and the dorsal epidermis extended and showed the arrangement of microfilaments along the cranio-caudal axis in the control embryos but not in the treated embryos. The dorsal region of the trunk neural tube in the control embryos consisted of a seam of neuroepithelial cells in which microfilaments were apparently arranged along the cranio-caudal axis but the region in the treated embryos was crowded with the neuroepithelial cells piled up randomly and microfilaments showed no arrangement. These results suggest that changes in the shapes and arrangement of the cells in the dermatome, the dorsal region of the trunk neural tube, and the dorsal epidermis cause extension of these tissues along the cranio-caudal axis and result in axial rotation. Microfilaments may play an essential role in changes in the shapes and arrangement of the cells in these tissues.
\end{abstract}

In murine embryos, axial rotation occurs at an early developmental stage and U-shaped embryos (the dorsal side of the upper half of the body facing the dorsal side of the lower half) become C-shaped with the opening the $\mathrm{C}$ directed ventrally $(1,2,9,2,14)$. In the mouse, this process is completed in embryos at the 13 somite stage (8). Rat embryos assume a C-shape at the 14 somite stage (5). Recently, Csk-deficient mouse embryos were generated by gene targeting (6). Csk is a cytoplasmic protein-tyrosine kinase that inactivates members of the Src family of protein-tyrosine kinases. Protein-tyrosine kinases are known to play essential roles in the signal transduction pathways that regulate cell proliferation, differentiation, and function. Csk-deficient embryos were developmentally arrested at the 10 to 12 somite stage and died at the neural stage. They did not show axial rotation. Thus, axial rotation seems to be one of the most important morphogenetic movements in murine embryos.

Rough (9) suggested that growth of the foregut and hindgut initiate axial rotation. Poelmann et al. (8) postulated a causal relationship between mitotic activity in the neural tube and axial rotation. From transection experiments and cinematographic studies, Deuchar $(1,2)$

\footnotetext{
$\dagger$ To whom correspondence should be addressed.
}

and Deuchar and Parker (3) concluded that development of the heart and contraction of ventral embryonic tissues, together with initial asymmetry of the axis and tension in the amnion, may contribute to axial rotation. In our previous report (5), we suggested that an increase in length of the dorsal part of somites along the craniocaudal axis of the body was the cause of axial rotation. However, in the Csk-deficient embryos, the heart, the gut, muscle, and epithelium developed beyond the 12 somite stage, although the trunk region of the neural tube showed an irregular shape accompanied with a great number of necrotic cells. Thus it is necessary to identify the tissues that are responsible for axial rotation, and to determine how they induce axial rotation.

Axial rotation in rats is inhibited by cytochalasin D (5). Cytochalasins have been shown to affect the polymerization of actin $(4,10)$. The growth of microfilaments is inhibited and preformed microfilaments are fragmented by treatment with cytochalasins (13). In the present study, to identify the tissues that are responsible for axial rotation, we first compared the pattern of distribution of microfilaments between the control rotated embryos and the cytochalasin D-treated non-rotated embryos using rhodamine-conjugated phalloidin. Our results showed that cytochalasin D disturbed the appearance of microfilaments in the dermatome, the dorsal re- 
gion of the trunk neural tube, and the dorsal epidermins. The changes in both the shapes and arrangement of the cells in these tissues were then examined quantitatively and observed by electron microscopy. The patterns of distribution of microfilaments and microtubules were also examined under the electron microscope.

\section{MATERIAL AND METHODS}

Breeding and staging of embryos. Female SpragueDawley (SD) rats (Slc: SD strain; Japan SLC., Inc., Shizuoka, Japan) were housed overnight with males in breeding rooms with a 12-h light cycle, constant temperature (24士 $2^{\circ} \mathrm{C}$ ), and constant humidity $(55 \pm 10 \%)$. Noon of the day on which a vaginal plug was observed was designated as day 0.5 of gestation.

Embryo culture. Embryos at the head-fold stage (9.5 days of gestation, with an egg cylinder length of 1.6-1.8 mm) were cultured in rat serum by the method of New et al. (1976). After 27 hours in culture, cytochalasin D (Sigma Chemical Co., St. Louis, MO, U.S.A.) was added at $0.1 \mu \mathrm{g} / \mathrm{ml}$ (final concentration) as described by Matsuda (1991). The embryos were cultured for a further 5 hours.

Histochemical procedures. Cultured embryos were fixed in $95 \%$ ethanol that contained $1 \%$ acetic acid at room temperature (RT) for one hour, dehydrated in a graded ethanol series, embedded in paraffin through xylene, and sectioned sagittally or transversely at $10 \mu \mathrm{m}$. Sections were put on slide glasses and deparaffinized. Deparaffinized sections were washed with $20 \mathrm{mM}$ Tris buffer that contained $0.15 \mathrm{M} \mathrm{NaCl}$ (pH 7.5), incubated for $30 \mathrm{~min}$ at $37^{\circ} \mathrm{C}$ with rhodamine-conjugated phalloidin (Wako Chemical Ind., Ltd., Osaka, Japan) that had been diluted $1: 20$ in the buffer. Sections were washed three times with the buffer, enclosed in glycerin jerry ( $7 \%$ gelatin in $50 \%$ glycerin containing $0.02 \%$ sodium azaid), and examined under a fluorescence microscopy (Fluophoto; Nikon, Tokyo, Japan).

Estimation of cell density. Cell numbers in each somite were counted and cell densities of the neural tube and of the dorsal epidermis in the mid-region of the body were measured in 27-h-cultured, 32-h-cultured, and cytochalasin D-treated 32-h-cultured embryos. Since somites separated into two layers, the dermatome and the myotome and sclerotome, cell numbers in each layer were counted in individual $10 \mu \mathrm{m} \mathrm{sag-}$ gital sections and the total number of those on individual sections were calculated for every somite by reference to serial sections. The trunk neural tube in para-saggital sections adjacent to a mid-saggital section of embryos was divided into three equal areas, a dorsal, a lateral, and a ventral part. Cell numbers per unit area were counted with reference to these parts under a light microscope with a calibrated grid. Cell numbers per unit length of the dorsal epidermis in para-saggital sections adjacent to a mid-saggital section were also counted under a light microscope with a calibrated grid.
Electron microscopy. Embryos cultured for 27 hours or for 32 hours with or without cytochalasin D were fixed in 2\% glutaraldehyde (TAAB Laboratories Equipment Ltd., Berks, England) in Hank's solution for 1.5 hours at $4^{\circ} \mathrm{C}$. Some embryos were immersed overnight in $10 \%$ glycerin in Hank's solution that contained $10 \mathrm{mM} \mathrm{MgCl} 2$ before fixation. Both types of specimen were postfixed in $0.5 \% \mathrm{OsO}_{4}$ (TAAB) in $0.1 \mathrm{M}$ phosphate buffer ( $\mathrm{pH}$ 7.0) for 1 hour, dehydrated with ethanol, and embedded in Quetol 812 (Nissin EM Co., Ltd., Tokyo, Japan). Thin sections were cut in a Porter-Blum MT 2-B ultramicrotome (Ivan Sorvall Inc., Norwalk, CT, U.S.A.), double-stained with uranyl acetate and lead citrate, and examined under an electron microscope $(\mathrm{H}-7000$; $\mathrm{Hi}-$ tachi, Ltd., Tokyo, Japan).

\section{RESULTS}

As described previously (Matsuda, 1991), 27-h-cultured embryos were U-shaped. After $32 \mathrm{~h}$ in culture, they became C-shaped. By contrast, 32-h-cultured cytochalasin D-treated embryos were not $\mathrm{C}$-shaped. The treated embryos remained U-shaped even after $48 \mathrm{~h}$ in culture.

Histochemical observations. Staining with rhodamine-conjugated phalloidin was observed in many tissues of the control rotated embryos (data not shown). Among these tissues the dermatome, the dorsal region of the trunk neural tube, and the dorsal epidermis showed no staining and/or less staining in the treated non-rotated embryos compared with the control embryos (Figs. 1b, 1c, 1e, 1f, 2b, 2e, 2f, 2c, 3b, 3c, 3e, and 3f).

As control embryos developed, somites appeared to be trapezoidal, with a short dorsal side and a long ventral side, changed their configuration, and became a reversed trapezoid, with a long dorsal side and a short ventral side for the sagittal sections that were examined. Their dorsal side constituted the dermatome in which the intense staining was observed (Fig. 1b). The staining was arranged along the cranio-caudal axis of the body in the base and the apical of the dermatome. However, the arrangement of the staining along the dorso-lateral direction was obscure in the transverse section of the dermatome (Fig. 1e). Cytochalasin D prevented this configuration change. In the cytochalasin D-treated embryos, the staining in the dermatome was weaker than that of the control embryos and was not oriented along the cranio-caudal axis (Figs. 1c and 1f). In 27-h-cultured U-shaped embryos, the staining was observed in the base of the dermatome, although it was very weak (Figs. 1a and 1b).

In the control embryos, neuroepithelial cells in the dorsal region of the trunk neural tube were arranged in an orderly manner and their outer surface was smooth, and the staining in the base and the apical of the region 

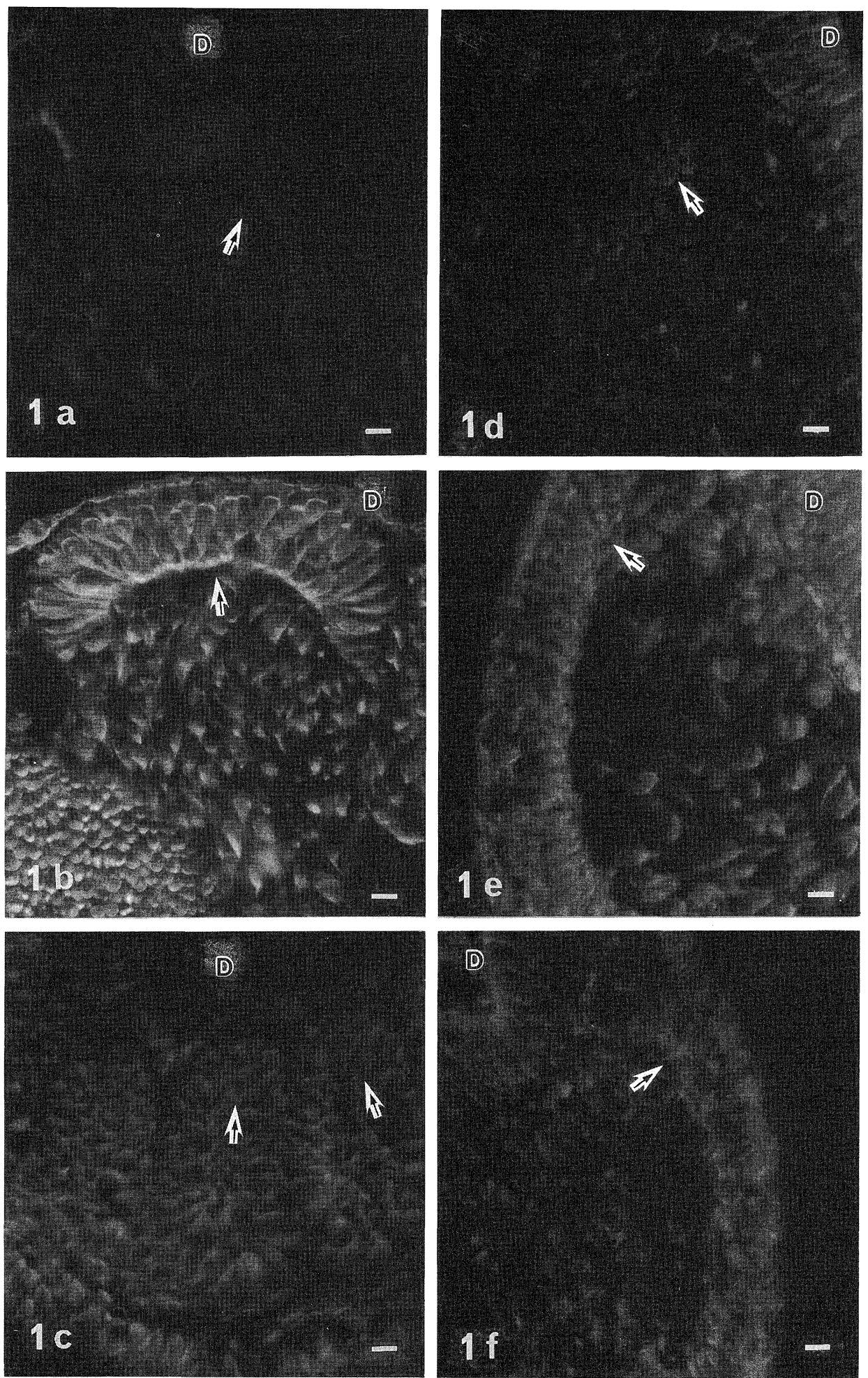

Fig. 1. Histochemical staining with rhodamine-conjugated phalloidin. Sagittal and transverse sections of somites from 27 -h-cultured (1a and 1d), 32-h-cultured ( $1 \mathrm{~b}$ and 1e), and 32-h-cultured cytochalasin D-treated (1c and $1 \mathrm{f}$ ) rat embryos. In 1a and 1d, a very weak staining is observed in the base of dermatome. In $1 \mathrm{~b}$, staining is apparent in the dermatome along the crani-cualdal axis. In 1e, staining is seen but seemed to be discontinious along the dorso-lateral direction. In $1 \mathrm{c}$ and $1 \mathrm{f}$, a weak staining is seen in dermatomes. Arrows indicate dermatomes. $\mathrm{D}$, dorsal direction; bar, $10 \mu \mathrm{m}$. 
seemed to be continuous along the cranio-caudal axis as far as observed in the sagittal section (Fig. 2b). The staining in the base of the region in the transverse section was discontinuous, while the staining in the apical was arranged so as to be oriented along the dorso-later- al direction (Fig. 2e). In the part of the neural tube under the roof plate, the staining was arranged along the long axis of the neuroepithelial cells (Fig. 2e). By contrast, the dorsal region of the trunk neural tube of the treated embryos was crowded with the neuroepithelial
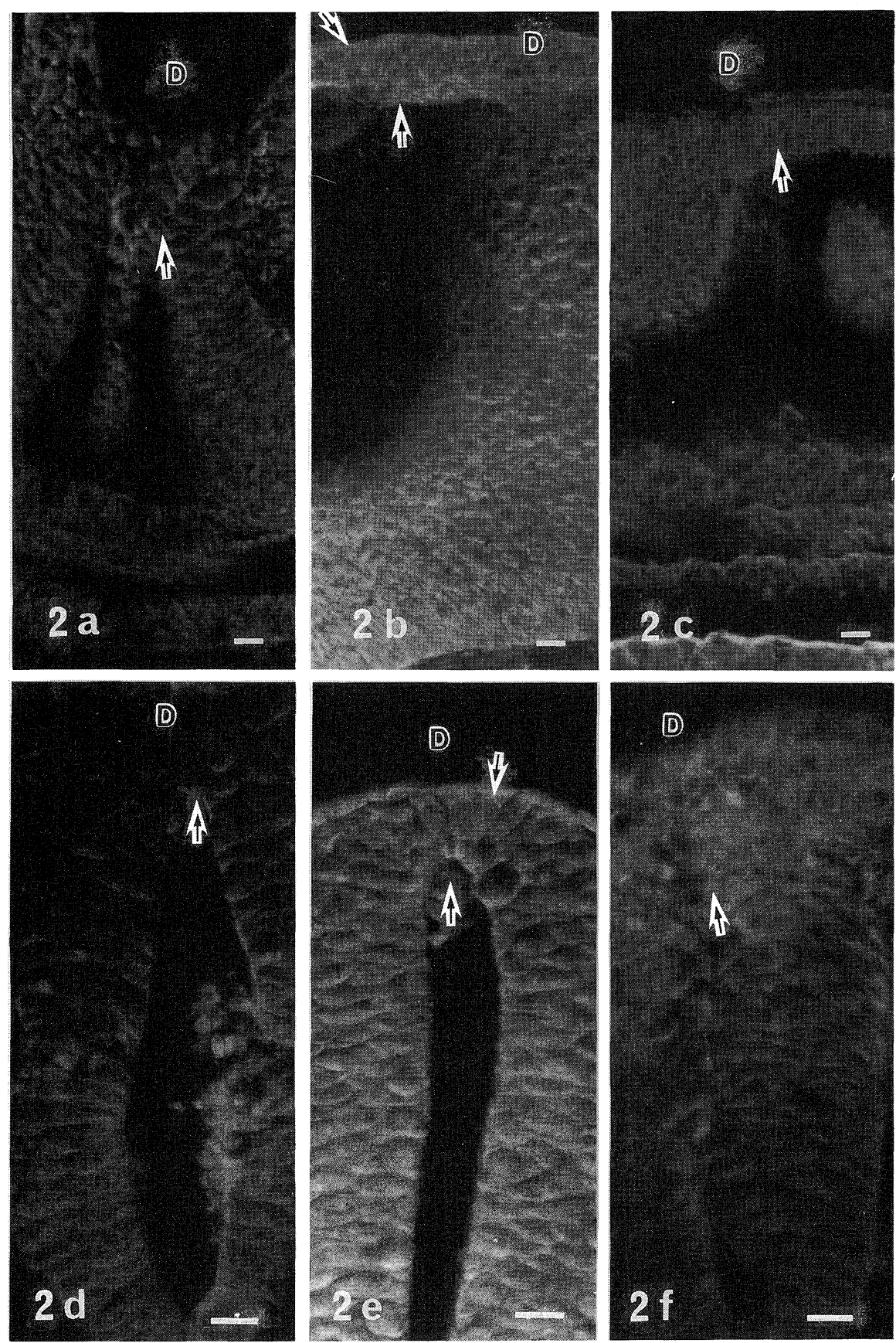

Fig. 2. Histochemical staining with rhodamine-conjugated phalloidin. Sagittal and transverse sections of the trunk neural tube in the mid-region of 27 -h-cultured ( $2 \mathrm{a}$ and $2 \mathrm{~d}$ ), 32-h-cultured ( $2 \mathrm{~b}$ and $2 \mathrm{e}$ ), and 32-h-cultured cytochalasin D-treated ( $2 \mathrm{c}$ and $2 \mathrm{f}$ ) rat embryos. In $2 \mathrm{a}$ and $2 \mathrm{~d}$, some cells in the neural tube show the staining. In $2 \mathrm{~b}$ and $2 \mathrm{e}$, the arranged staining is seen in the dorsal region of the neural tube, while the staining in the ventral region is vague. In $2 \mathrm{c}$ and $2 \mathrm{f}$, the vague staining is seen in the dorsal region of the neural tube, while the arranged staining is seen in the ventral region. Arrows indicate the dorsal region of the neural tube. D, dorsal direction; bar, $15 \mu \mathrm{m}$. 
cells, and the staining in the region was weak and seemed to show no arrangement (Fig. 2f). In the sagittal section, although the part of the neural tube under the roof plate in the treated embryos showed very weak staining, relatively intense staining was observed in the ventral region of the neural tube (Fig. 2c). The dorsal region of the trunk neural tube of the U-shaped embryos at the early developmental stage consisted of randomly arranged neuroepithelial cells and some of these cells showed the staining (Fig. 2a).

The dorsal epidermal cells in the mid-region of the body elongated more along the cranio-caudal axis and the dorso-lateral direction in the control embryos than those in the treated embryos (Figs. 3b, 3c, 3e, and 3f). In the sagittal section, staining was observed in the dorsal epidermis and arranged along the cranio-caudal axis in the control embryos (Fig. 3b) but not in the treated embryos (Fig. 3c). By contrast, staining was observed in the transverse sections both of the control and the treated embryos, although the staining in the former was arranged along the dorso-lateral direction but not in the latter (Figs. 3e and 3f). The U-shaped embryos at
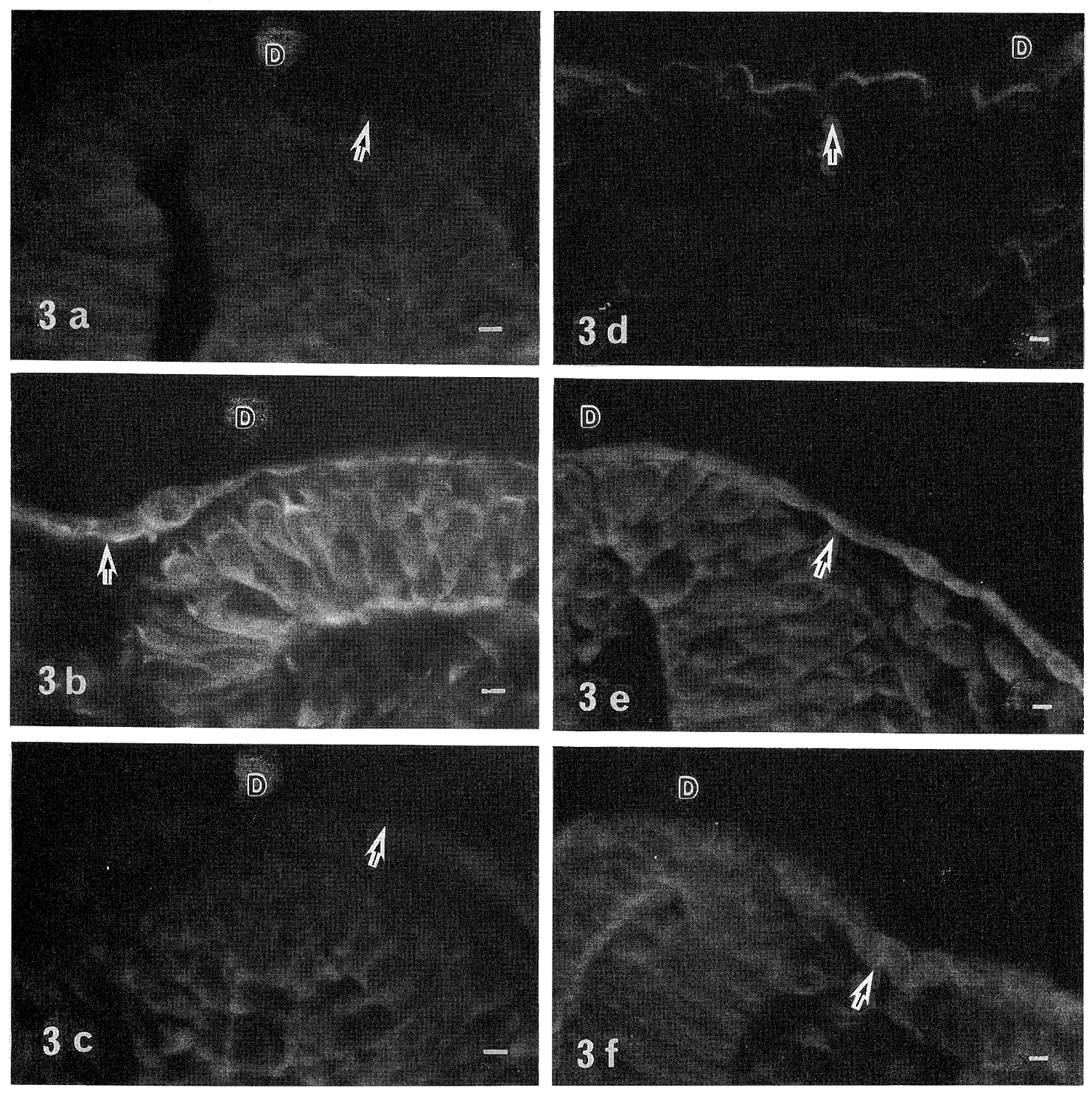

Fig. 3. Histochemical staining with rhodamine-conjugated phalloidin. Sagittal and transverse sections of the dorsal epidermis in the mid-region of 27-h-cultured ( $3 \mathrm{a}$ and $3 \mathrm{~d}$ ), 32-h-cultured ( $3 \mathrm{~b}$ and $3 \mathrm{e}$ ), and 32-h-cultured cytochalasin D-treated ( $3 \mathrm{c}$ and $3 \mathrm{f}$ ) rat embryos. In $3 \mathrm{a}$, the dorsal epidermis is not stained, while staining is seen along the dorso-lateral direction in $3 \mathrm{~d}$. In $3 \mathrm{~b}$ and $3 \mathrm{e}$, the intense staining is seen in the dorsal epidermis along both the cranio-caudal axis and the dorso-lateral direction. In $3 \mathrm{c}$, no staining is seen in the dorsal epidermis, while vague staining is seen in $3 \mathrm{f}$. Arrows indicate the dorsal epidermis. D, dorsal direction; bar, $5 \mu \mathrm{m}$. 
the early developmental stage showed no staining in the dorsal epidermis in the sagittal section (Fig. 3a) as with the treated embryos, but the staining was observed along the dorso-lateral direction in the transverse sec- tion (Fig. 3d).

Estimation of cell density. Figure 4 shows cell numbers of the dermatome and of the myotome and sclerotome of each somite positioned on the right side of the
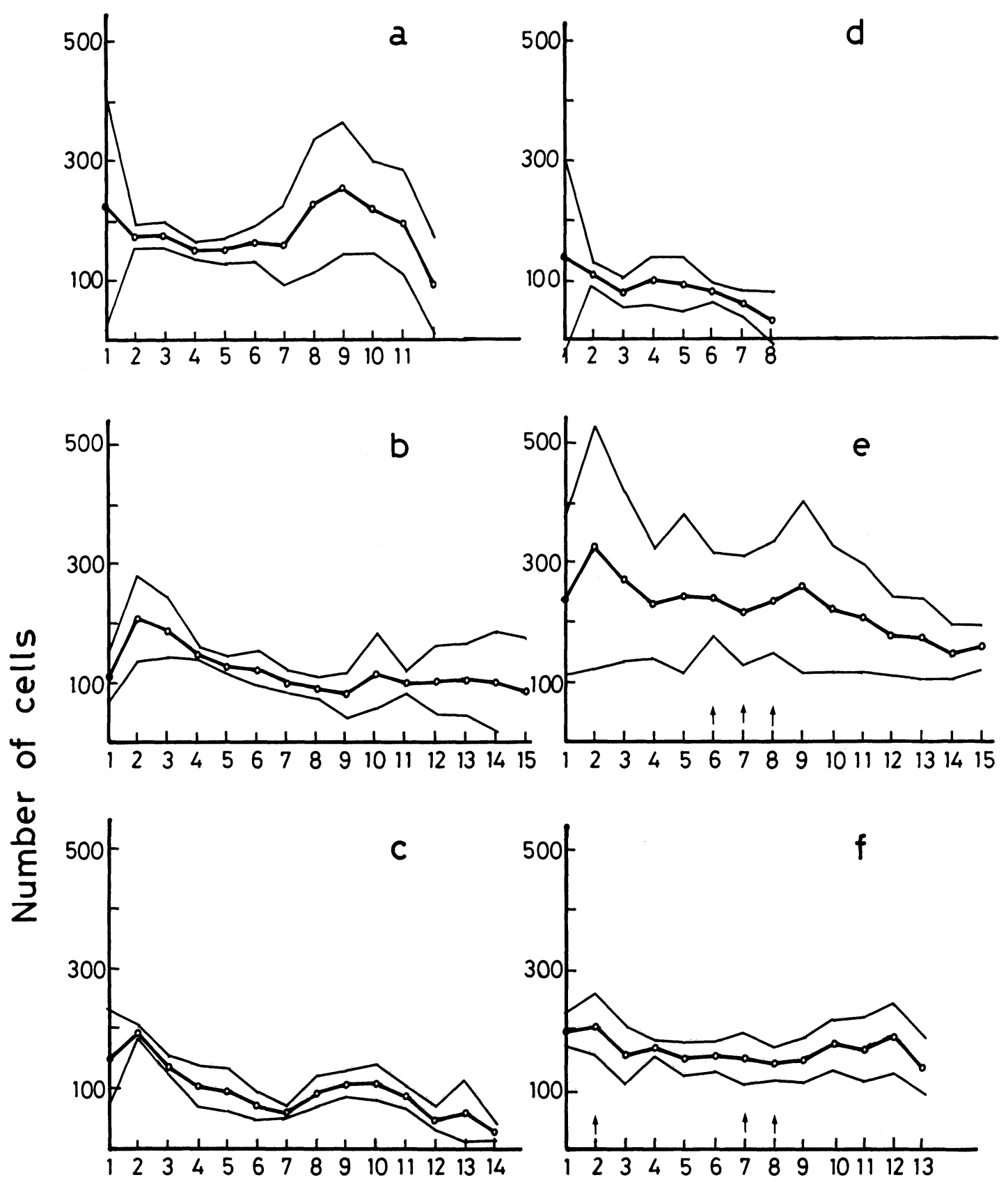

\section{Somites}

Fig. 4. Cell numbers (ordinate) in the dermatome (left colum) and in the myotome and sclerotome (right colum) in each somite (abscissa) on the right side of 27 -h-cultured ( $4 \mathrm{a}$ and $4 \mathrm{~d}$ ), 32-h-cultured ( $4 \mathrm{~b}$ and $4 \mathrm{e}$ ) and 32-h-cultured cytochalasin D-treated (4c and $4 \mathrm{f}$ ) rat embryos. The data represent means \pm S.D. of results from three samples. Thick solid line indicates cell numbers. Thin solid line represents standard deviation. Upward arrows indicate statistically significant increase in cell numbers over those in the corresponding parts of 27 -h-cultured embryos $(\mathrm{P}<0.05$, Student's t test). 
body. Cell numbers of the corresponding dermatomes did not change during axial rotation. By contrast, cell numbers of the myotome and sclerotome in the mid-re- gion of the body increased during axial rotation of control embryos and a similar increase was also observed in the treated embryos, although the treated embryos did
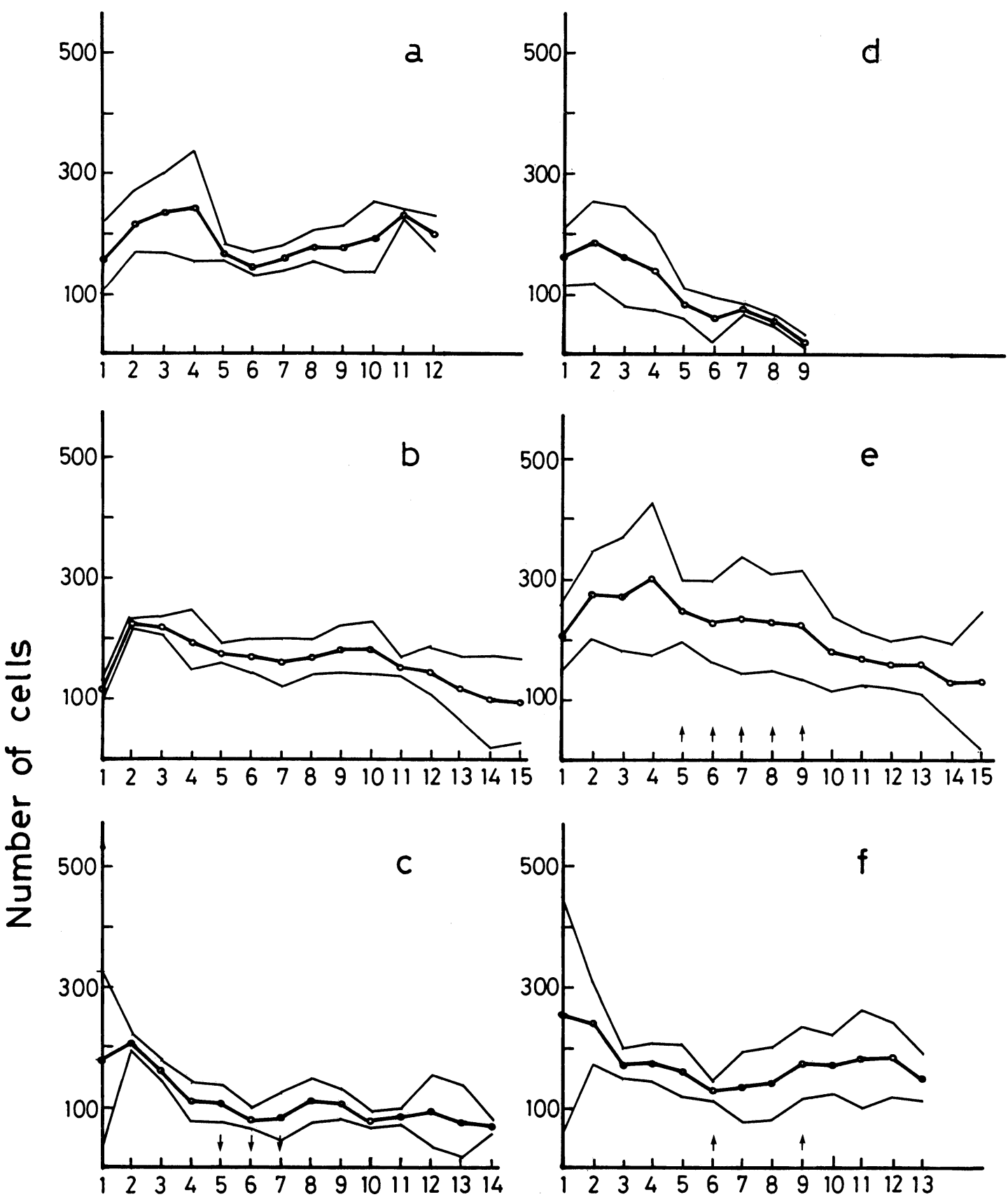

\section{Somites}

Fig. 5. Cell numbers (ordinate) in the dermatome (left colum) and in the myotome and sclerotome (right colum) in each somite (abscissa) on the left side of 27-h-cultured ( $5 \mathrm{a}$ and $5 \mathrm{~d}$ ), 32-h-cultured ( $5 \mathrm{~b}$ and 5e) and 32-h-cultured cytochalasin D-treated (5c and 5f) rat embryos. The data represent means \pm S.D. of results from three samples. Thick solid line indicates cell numbers. Thin solid line represents standard deviation. Upward or downward arrows indicate statistically significant increase or decrease in cell numbers over those in the corresponding part of 27-h-cultured embryos $(\mathrm{P}<0.05$, Student's $\mathrm{t}$ test $)$. 
Table I. The Cell Density in the trunk neUral tube of Rat embryos treated With Cytochalasin D.

\begin{tabular}{lccc}
\hline \multirow{2}{*}{ Embryos } & \multicolumn{3}{c}{ Neural tube $($ Cells/mm² } \\
\cline { 2 - 4 } & Dorsal & Lateral & Ventral \\
\hline 27-h-cultured & $481 \pm 167(9)^{@}$ & $519 \pm 185(9)^{@}$ & $611 \pm 74(9)^{@}$ \\
32-h-cultured (control) & $630 \pm 56(24)^{*}$ & $611 \pm 56(24)^{*}$ & $685 \pm 74(24)^{*}$ \\
32-h-cultured (+ cytochalasin D) & $714 \pm 74(21)^{* @}$ & $727 \pm 80(21)^{* @}$ & $723 \pm 78(21)^{*}$ \\
\hline
\end{tabular}

Rat embryos at the head-fold stage (9.5 days of gestation, with an egg cylinder length of 1.6-1.8 mm) were cultured in rat serum (4 embryos $/ 4 \mathrm{ml}$ ) for 27 hours (27-h-cultured). Then $0.1 \mathrm{ml}$ of Hank's solution with ( + cytochalasin D) or without (control) cytochalasin D (final concentration, $0.1 \mu \mathrm{g} / \mathrm{ml}$ ) was added to the culture medium and embryos were cultured for a further 5 hours (32-h-cultured). Then embryos were fixed, embedded in paraffin, and cut into $10-\mu \mathrm{m}$ sagittal sections. In para-sagittal sections, the trunk neural tube in the mid-region of the body was divided into three equal areas, a dorsal, a lateral, and a ventral part. Cell numbers per unit area were counted with reference to these parts under a light microscope with a calibrated grid. Mean \pm S.D.

* Significantly different from the value for 27-h-cultured embryos.

(a) significantly different from the value for 32 -h-cultured (control) embryos. ( $\mathrm{P}<0.05$, Student's $\mathrm{t}$ test).

Numbers in parentheses represent numbers of samples.

not show axial rotation. In the left-sided somites, almost the same results were obtained (Fig. 5), with the exception that cell numbers in some dermatomes in the mid-region of the body decreased during the treatment with cytochalasin $\mathrm{D}$.

The cell density in the trunk neural tube in the mid-region of the body increased as the culture progressed irrespective of whether or not embryos were treated with cytochalasin D (Table I). The degree of increase was different between control and treated embryos. The cell density in the dorsal and the lateral part of the neural tube in para-saggital sections of the treated embryos were highre than that of the control embryos. By contrast, there was no apparent difference in the cell density in the ventral part of the neural tube in para-saggital sections between control and treated embryos.

The cell density in the dorsal epidermis in the mid-region of the body became low during axial rotation (Table II). Treatment with cytochalasin D did not induce this lowering (Table II).

Electron microscopic observations. In the dermatome of the U-shaped embryos at the eraly developmental stage, the cytoplasm was characterized by a large number of ribosomes with features typical of embryonic cells (Fig. 6a). Microfilaments were scarcely observed and microtubules were sometimes seen under cell membranes. As axial rotation proceeded, the apices of the cells positioned in the edges of the dermatome became wider than their bases (they were wedge-shaped cells) accompanied with elongation of their long axes (Fig. 6b). Microfilaments were frequently seen within the periphery of these cells (Fig. 6c). Microtubules ran parallel to the long axes of the cells. Cytochalasin D intercepted expansion of the apical surfaces and elongation of long axes of the cells in the dermatome (data not shown). In these cells, microfilaments were scarcely observed, but microtubules were distributed under cell membranes (Fig. 6d).

Before axial rotation, neuroepithelial cells in the dorsal part of the trunk neural tube in the mid-region of the body were tightly packed together and those facing the diocoel made contact with the zonula adherens. Membranous structures were rare and microfilaments were observed within the periphery of these cells but were not conspicuous. Mictotubules were sometimes seen under cell membranes (Fig. 7a). After axial rotation, the neuroepithelial cells in the dorsal part of the trunk neural tube in the mid-region of the body were rather loosely associated with one another. In these cells, membranous structures increased. Microfilaments were frequently observed and sometimes resembled stress fibers (Fig. 7b). Microtubules ran parallel to the long axes of the cells. The treatment of cytochalasin D prevented dispersion of the neuroepithelial cells. No mi-

Table II. The Cell Density IN THE DORSAL EPIDERMis OF RAT EMBRYOS TREATED WITH CYTOCHALASIN D.

\begin{tabular}{lc}
\hline Embryos & Dorsal epidermis (cells/mm) \\
\hline 27-h-cultured & $38 \pm 21(22)$ \\
32-h-cultured (control) & $17 \pm 2(40)^{*}$ \\
32-h-cultured (+ cytochalasin D) & $37 \pm 4(14)$ \\
\hline
\end{tabular}

Rat embryos at the head-fold stage (9.5 days of gestation, with an egg cylinder length of $1.6-1.8 \mathrm{~mm})$ were cultured in rat serum (4 embryos $/ 4 \mathrm{ml}$ ) for 27 hours (27-h-cultured). Then $0.1 \mathrm{ml}$ of Hank's solution with (+ cytochalasin D) or without (control) cytochalasin D (final concentration, $0.1 \mu \mathrm{g} / \mathrm{ml}$ ) was added to the culture medium and embryos were cultured for a further 5 hours (32-h-cultured). Then embryos were fixed, embedded in paraffin, and cut into $10-\mu \mathrm{m}$ sagittal sections. In mid-sagittal sections, cell numbers per unit length in the dorsal epidermis in the mid-region of the body were counted under a light microscope with a calibrated grid. Mean \pm S.D.

* significantly different from the value for 27-h-cultured embryos. $(\mathrm{P}<0.05$, Student's $\mathrm{t}$ test $)$.

Numbers in parentheses represent numbers of samples. 

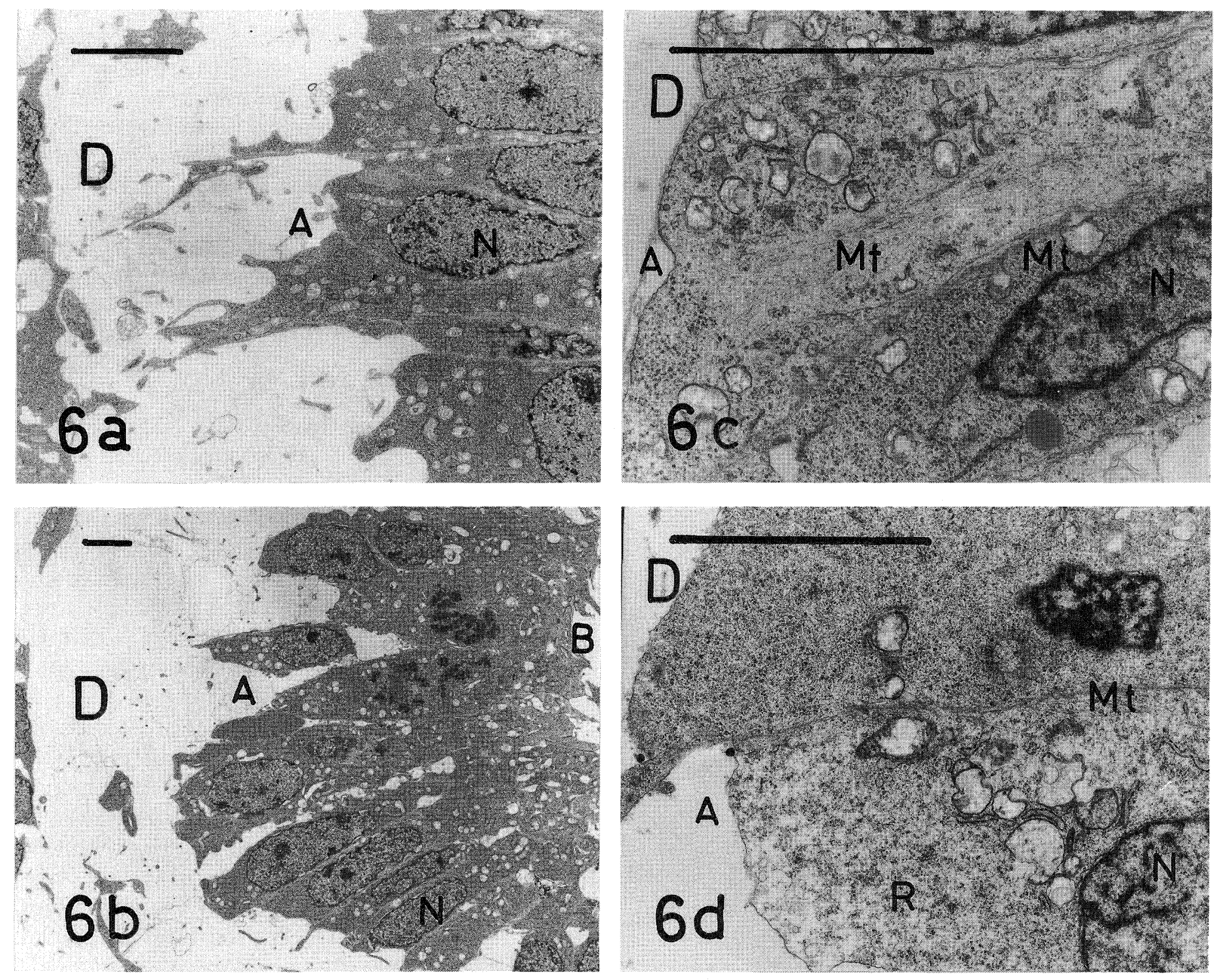

Fig. 6. Electron micrographs of the dermatome in sagittal sections of 27 -h-cultured (6a), 32-h-cultured (6b and 6c), and 32-h-cultured cytochalasin D-treated (6d) rat embryos. Specimens were treated with $10 \%$ glycerin. 6a shows the arrangement of cells and nuclei. The cytoplasm is characterized by a large number of ribosomes. In $6 \mathrm{~b}$, the cells in the edges of the dermatome are elongated. Microfilaments and microtubules run parallel to the long axis of the cell (6c). In $6 \mathrm{~d}$, no microfilaments are seen but microtubules are visible under the cell membrane. A, apex of cells; $\mathrm{B}$, base of cells; D, dorsal direction; Mf, microfilament; Mt, microtubule; N, nucleus; R, ribosome; bar, $5 \mu \mathrm{m}$.

crofilaments were detected in these cells in the sagittal section despite a careful electron-microscopic examination, although microtubules were numerous (Fig. 7c).

At the early developmental stage, the dorsal epidermis in the mid-region of the body was composed of a single layer of cells which were attached to the zonula adherens on the outer side of the cell periphery (Fig. $8 a)$. No microfilaments were seen in these cells in the sagittal sections despite a careful electron-microscopic examination. Some of the microtubules observed under cell membranes were close to the zonula adherens. After axial rotation, the dorsal epidermis became thin, in which nuclei were rather dispersed (Fig. 8c). Microfilaments were seen rarely within the cells (data not shown). In cytochalasin D-treated embryos, nuclei in the dorsal epidermis were roundish in shape and pro- truded from cell bodies. No microfilaments were seen in these cells in the sagittal section despite a careful electron-microscopic examination (Fig. 8d).

\section{DISCUSSION}

Axial rotation in rat embryos takes place during the 5 hours from about day 10.6 to day 10.8 , and this process is inhibited by cytochalasin $\mathrm{D}(0.1 \mu \mathrm{gml})$, which has no apparent effects on the replication of DNA and protein synthesis in the embryos (5). The results of the present study showed that cytochalasin $\mathrm{D}$ disturbed appearance of microfilaments in the dermatome, the dorsal region of the trunk neural tube, and the dorsal epidermis, although microfilaments appeared in these tissues of the normally developing embryos during the period of axial 

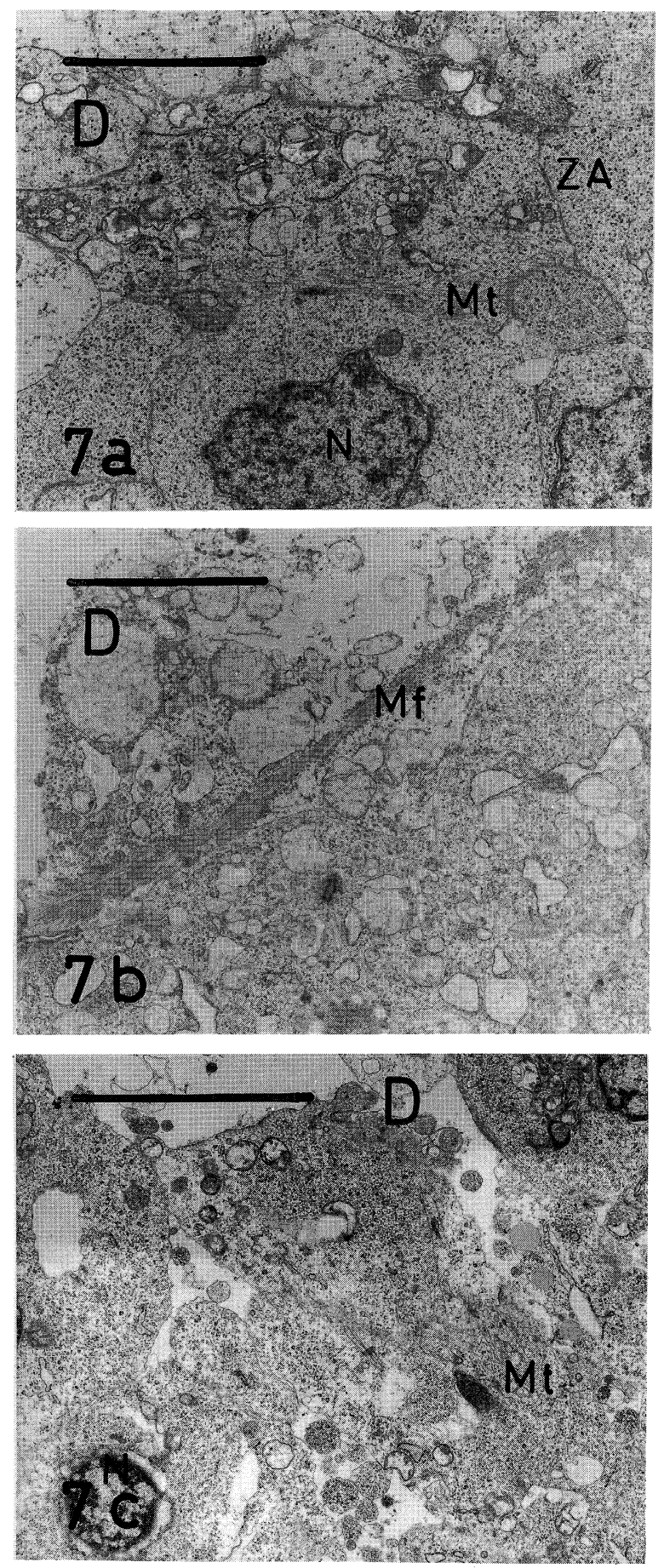

Fig. 7. Electron micrographs of the dorsal region of the trunk neural tube in sagittal sections in the mid-region of 27-h-cultured (7a), 32h-cultured (7b), and 32-h-cultured cytochalasin D-treated (7c) rat embryos. Specimens were treated with $10 \%$ glycerin. In $7 \mathrm{a}$, microtubules can be observed in the cytoplasm but very few microfilaments are detectable. In $7 \mathrm{~b}$, a bundle of microfilaments can be seen under the cell membrane. In $7 \mathrm{c}$, microtubules run randomly through the cytoplasm. No microfilaments can be seen. D, dorsal direction; Mf, microfilaments, Mt, microtubules; N, nucleus, ZA, zonula adherens; bar, $5 \mu \mathrm{m}$. rotation. These results indicated that the dermatome, the dorsal region of the trunk neural tube, and the dorsal epidermis are responsible for axial rotation. Some investigators have suggested that the foregut and hindgut (9) or the neural tube (8) are responsible for axial rotation. Their suggestions were derived only from descriptive studies, and it was unclear whether or not these tissues were actively involved in axial rotation. Deuchar (1) has reported that the heart and ventral embryonic tissues are responsible for axial rotation. However, the experimental technique used by Deuchar can be described as a form of "severance," and any direct causation of axial rotation by the heart or ventral embryonic tissues was obscure. In Csk-deficient embryos, the trunk region of of the neural tube showed an irregular shape but the heart, hindgut, the liver primordium, muscle, and epithelium appeared to be normal (6). These results suggest that the trunk neural tube correlated intimately with axial rotation but not the heart, ventral embryonic tissues, the gut, muscle, and epithelium. According to the histological pictures of the Csk-deficient embryos, however, dermatomes of somites seemed to be nascent and the dorsal epithelial cells also seemed to be compactly arranged.

Axial rotation is a complex multifactorial process driven by multiple cell behaviours occurring simultaneously. How do the dermatome, the dorsal region of the trunk neural tube, and the dorsal epidermis behave during axial rotation? The results of the present experiment indicated that the dermatome become extended along the cranio-caudal axis of the body during axial rotation. Our analysis of the way in which the dermatome extends revealed that the extension was accompanied by changes in the shapes and arrangement of cells but not by an increase in cell number. Cells along the edges of the dermatome enlarged their apical cell surfaces and became wedge-shaped as axial rotation proceeded but this enlargement was not observed in the treated embryos. The roof plate of the trunk neural tube consisted of a thin layer of neuroepithelial cells arranged systemetically in the control rotated embryos but not in the treated non-rotated embryos. The dorsal region of the neural tube in the latter was composed of thick multiple-layered neuroepithelial cells which were distributed randomly and crowded more intensely than the former embryos. The sparse arrangement of the cells and a seam of the cells observed in the control embryos orchestrated to the expansion of the dorsal region of the trunk neural tube, while the region in the treated embryos did not expand but retained its form. The dorsal epidermal cells elongated along the cranio-caudal axis during axial rotation in the control embryos but not in the treated non-rotated embryos. The elongation of the cells orchestrated into the extension of the dorsal epidermis along the cranio-caudal axis. Thus, these changes in shapes 

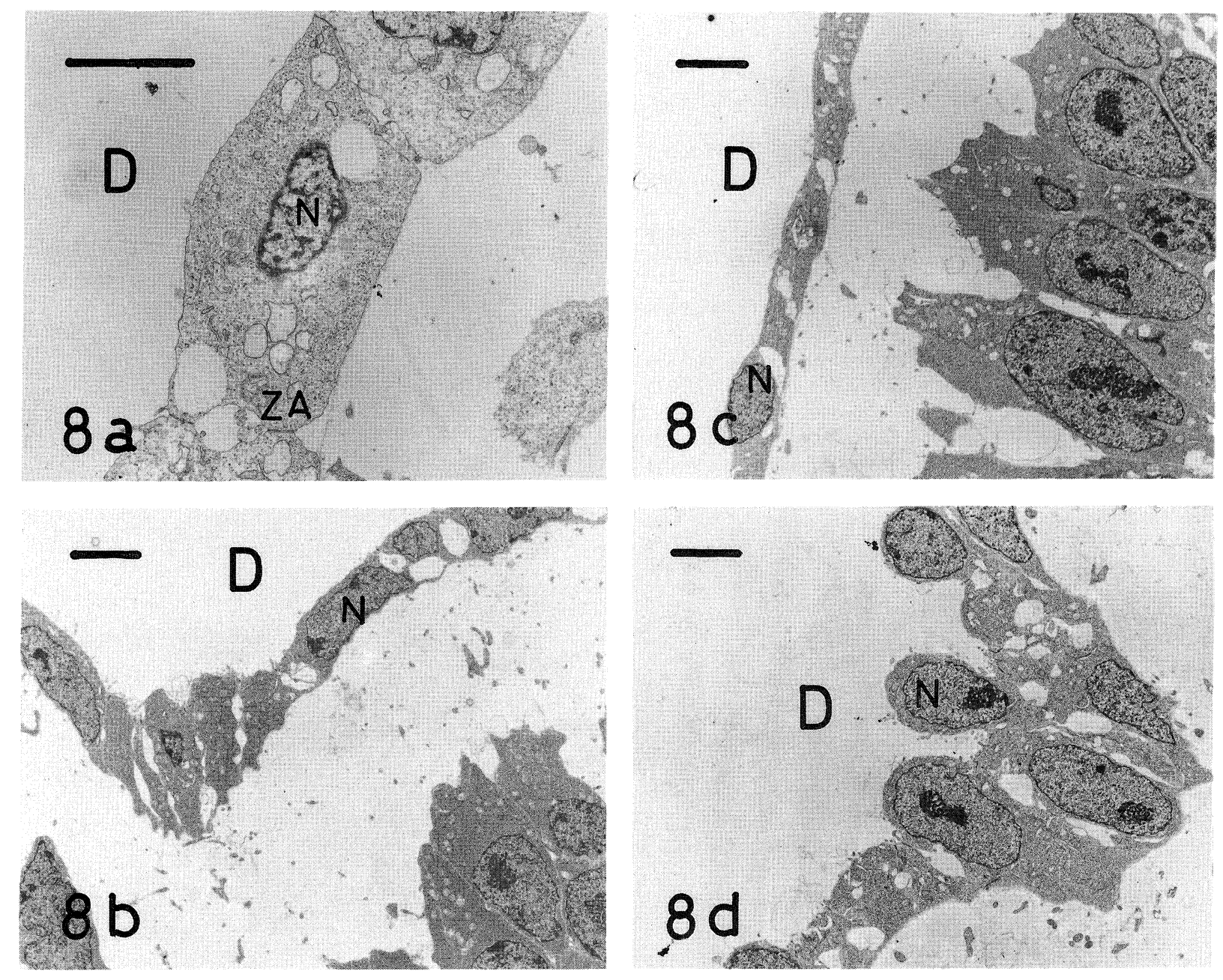

Fig. 8. Electron micrographs of the dorsal epidermis in sagittal sections in the mid-region of 27 -h-cultured (8a and 8b), 32-h-cultured (8c), and 32-h-cultured cytochalasin D-treated (8d) rat embryos. Specimens were treated with $10 \%$ glycerin. In $8 \mathrm{a}$, the cells are attached to the zonula adherens. In 8b, the dorsal epidermis is composed of a single layer of cells. $8 \mathrm{c}$ and $8 \mathrm{~d}$ show the arrangement of cells and nuclei. In $8 \mathrm{~d}$, nuclei protrude from the cytoplasm in some epidermal cells. $\mathrm{D}$, dorsal direction; N, nucleus, ZA, zonula adherens; bar, $5 \mu \mathrm{m}$.

and arrangement of the cells in the dermatome, the dorsal region of the trunk neural tube, and the dorsal epidermis may cause axial rotation through the extension of these tissues along the cranio-caudal axis.

The results of the present experiment indicated that the staining with rhodamine-conjugated phalloidin in the dermatome was arranged along the cranio-caudal axis in the control rotated embryos but not in the cytochalasin D-treated non-rotated embryos. The staining in the dorsal region of the trunk neural tube seemed to be contenious along the cranio-caudal axis in the control embryos but showed no arrangement in the treated embryos. The dorsal epidermis showed the staining arranged along the cranio-caudal axis in the control embryos but not in the treated embryos. Electron microscopic studies indicated that microtubules were observed in the cells of the dermatome, the dorsal part of the trunk neural tube, and the dorsal epidermis whether or not axial rotation occurred. These results suggest that microtubules are not responsible for axial rotation. Alignment of microfilaments may be responsible for the changes in shapes and arrangement of the cells in the dermatome, the dorsal region of the trunk neural tube, and the dorsal epidermis. Cell shape changes are the basis for a morphogenetic movement and microfilaments are required for the movement. It is not clear how microfilaments are organized during the course of axial rotation. In trochoblast differentiation, the formation of a band of F-actin in an indivisual trochoblast involves an antonomous process (11). Thus, it is possible that the organization of microfilaments in the dermatome, the dorsal region of the trunk neural tube, and the dorsal epidermis involves an autonomous process that take place during the course of axial rotation. 


\section{REFERENCES}

1. Deuchar, E.M. 1971. The mechanism of axial rotation in the rat embryos: An experimental study in vitro. J. Embryol. Exp. Morph., 25: 189-201.

2. DeUChaR, E.M. 1975. Reconstructive ability of axial tissue in early rat embryos after operation and culture in vitro. J. Embryol. Exp. Morph., 33: 217-226.

3. Deuchar, E.M. and Parker, F.M. 1975. Further observation on axial rotation in rat embryos. Acta Embryol. Exp. issue, 1: 55-68.

4. Maclean-Fletcher, S. and Pollard, J.D. 1980. Mechanism of action of cytochalasin B on actin. Cell, 20: 329-341.

5. Matsuda, M. 1991. Change of rat embryos from a dorsally concave U-shape to a dorsally convex C-shape. Develop. Growth \& Differ., 33: 117-122.

6. Nada, S., Yagi, T., TaKeda, H., Tokunaga, T., NaKagawa, H., IKawa, Y., OKada, M., and Aizawa, S. 1993. Constitutive activation of Src family kinases in mouse embryos that lack Csk. Cell, 73: 1125-1135.

7. New , D.A.T., Coppola, P.T., and Cockroft, D.L. 1976. Comparison of growth in vitro and in vivo of post-implantation rat embryos. J. Embryol. Exp. Morph., 36: 133-144.
8. Poelmann, R.E., Mentink, M.M., and Leewen, J.L. 1987. Axial rotation of murine embryos, a study of asymmetric mitotic activity in the neural tube of somite stages. Anat. Embryol., 176: $99-103$.

9. Rough, R. 1990. Chronology of development: 8-16 days. In The Mouse: Its Reproduction and Development (R. Rough, ed.). Oxford University Press, New York, pp 102-153.

10. Schliwa, M. 1982. Action of cytochalasin D on cytoskeletal networks. J. Cell Biol., 92: 79-91.

11. Serras, F. and SPEKSNIJDER, J.E. 1991. F-actin localization during trochoblast differentiation in Patella vulgata embryo. Development, 112: 833-845.

12. SNell, G.D. and SteVens, L.C. 1966. Early embryology. In Biology of the Laboratory Mouse 2nd. ed. (E.L. Green, ed.). McGraw-Hill, New York, pp 206-245.

13. SPOONER, B.S. 1978. Cytochalsons as probes in selected morphogenetic processes. In Cytochalasins: Biochemical and Cell Biological Aspects (S.W. Tanenbaum, ed.). Elsevier/North Holland Biomedical Press, Amsterdam, pp 65-89.

14. TheILeR, K. 1989. Atlas of embryonic development. In The House Mouse (K. Theiler, ed.). Springer-Verlag Inc., New York, pp. 21-65.

(Received for publication, July 21, 1994

and in revised form, September 22, 1994) 